\title{
Vertebral Artery Dissecting Aneurysm Causing Central Tapia's Syndrome: A Case Report
}

\author{
Yong Woo Shim, $\mathrm{MD}^{1, \star}$, Jung Hyun Park, $\mathrm{MD}^{2, \star}$, Sung-Tae Kim, $\mathrm{MD}^{1}$, Jin Wook Baek, $\mathrm{MD}^{3}$, \\ Hyun Gon Lee, $\mathrm{MD}^{4}$, Jung Hae Ko, MD, $\mathrm{PhD}^{5}$, Sung Hwa Paeng, MD, $\mathrm{PhD}^{1}$, Se Young Pyo, MD, $\mathrm{PhD}^{1}$, \\ Sung-Chul Jin, $\mathrm{MD}, \mathrm{PhD}^{4}$, Hae Woong Jeong, $\mathrm{MD}, \mathrm{PhD}^{3}$, Young Gyun Jeong, $\mathrm{MD}, \mathrm{PhD}^{1}$ \\ ${ }^{1}$ Department of Neurosurgery, Busan Paik Hospital, Inje University College of Medicine, Busan, Korea \\ ${ }^{2}$ Department of Neurosurgery, Kosin University Gospel Hospital, Kosin University College of Medicine, Busan, Korea \\ ${ }^{3}$ Department of Diagnostic Radiology, Busan Paik Hospital, Inje University College of Medicine, Busan, Korea \\ ${ }^{4}$ Department of Neurosurgery, Haeundae Paik Hospital, Inje University College of Medicine, Busan, Korea \\ ${ }^{5}$ Department of Endocrinology, Haeundae Paik Hospital, Inje University College of Medicine, Busan, Korea
}

The central type of Tapia's syndrome is an extremely rare presentation, characterized by unilateral paralysis of the vagal and hypoglossal nerves, contralateral hemiparesis, or hemihypesthesia. This report describes a case of a middle-aged patient who developed central Tapia's syndrome due to a right vertebral artery dissecting aneurysm (VADA). The patient complained about swallowing difficulty and odynophagia. Right vocal cord paralysis, mild tongue deviation to the right side, left hypesthesia, and decreased temperature sensation with left hemiparesis were observed in neurologic exams. A right VADA and compression of the medulla oblongata due to the VADA were diagnosed on magnetic resonance imaging. Endovascular flow diversion of the right VADA was performed. After 1 year, all neurological symptoms and vocal cord paralysis were nearly resolved, but left hypesthesia remained with decreased nociception. We present and discuss how a VADA caused those symptoms and propose endovascular flow diversion as a treatment option.

Key Words: Vertebral artery dissection; Endovascular procedures; Medulla oblongata; High-resolution magnetic resonance imaging; Tapia's syndrome

\section{INTRODUCTION}

In 1906, Antonio Garcia Tapia was the first to describe concomitant unilateral paralysis of the vagus and hypoglossal nerves. Tapia's syndrome can either be peripheral or central. ${ }^{2}$ Several reports exist regarding the peripheral type. - $^{3-9}$ In contrast, the central type is extremely rare; it is characterized by unilateral paralysis of the vagus and hypoglossal nerves with contralateral hemiparesis or hemihypesthesia. ${ }^{7}$ We describe and review a rare case in which the mass effects of a vertebral artery dissecting aneurysm (VADA) caused central Tapia's syndrome.

\section{CASE REPORT}

A middle-aged patient presented with complaints of odynophagia, cough with headache, and neck pain. Laryngoscopy

\section{Correspondence to: Sung-Tae Kim, MD Department of Neurosurgery, Busan Paik Hospital, Inje University College of Medicine, 75 Bokji-ro, Busanjin-gu, Busan 47392, Korea \\ Tel: +82-51-890-6144 \\ Fax: +82-51-898-4244 \\ E-mail: kimst015@hanmail.net \\ *These authors contributed equally to this paper.}

Received: February 10, 2021 Revised: June 17, 2021

Accepted: June 17, 2021

\section{Copyright $\odot 2021$ Korean Society of} Interventional Neuroradiology

This is an Open Access article distributed under the terms of the Creative Commons Attribution Non-Commercial License (http://creativecommons.org/licenses/by-nc/4.0) which permits unrestricted non-commercial use, distribution, and reproduction in any medium, provided the original work is properly cited. 
revealed right vocal cord palsy. On neurologic examination, we observed deviation of the tongue to the right and decreased nociception with hemiparesis on the left side.

Next, magnetic resonance angiography was performed and a right VADA was observed (Fig. 1A). High-resolution magnetic resonance imaging $(\mathrm{HR}-\mathrm{MRI})^{10}$ showed a lesion that was $12 \mathrm{~mm}$ in diameter, including a section that was partially thrombosed (Fig. 1B). Considering these findings, central Tapia's syndrome was strongly suspected due to compression of the medulla oblongata by the VADA.

After cerebral angiography (Fig. 1C), endovascular flow diversion of the VADA was chosen. The Artis zee biplane angiography system (Siemens, Erlangen, Germany) was used for angiography and endovascular monitoring. Considering the size of the aneurysm and the diameter of the parent artery, a $3.5 \times 30$ mm Pipeline Embolization Device (PED) (Medtronic, Irvine, CA, USA) was deployed to cover all parts of the aneurysm. Wall apposition of the PED to the vessel wall was confirmed by using Dynamic computed tomographic (Fig. 1D). Contrast stagnation in the VADA remained until the venous phase, and the O'Kelly-Marotta grading scale was A3. ${ }^{11}$ After endovascular PED, the headache disappeared and the patient was discharged. A follow-up HR-MRI 1 year later suggested complete obliteration, and the diameter of VADA was decreased (Fig. 1E). After 1 year, odynophagia, coughing, tongue deviation, and left hemiparesis were nearly resolved,
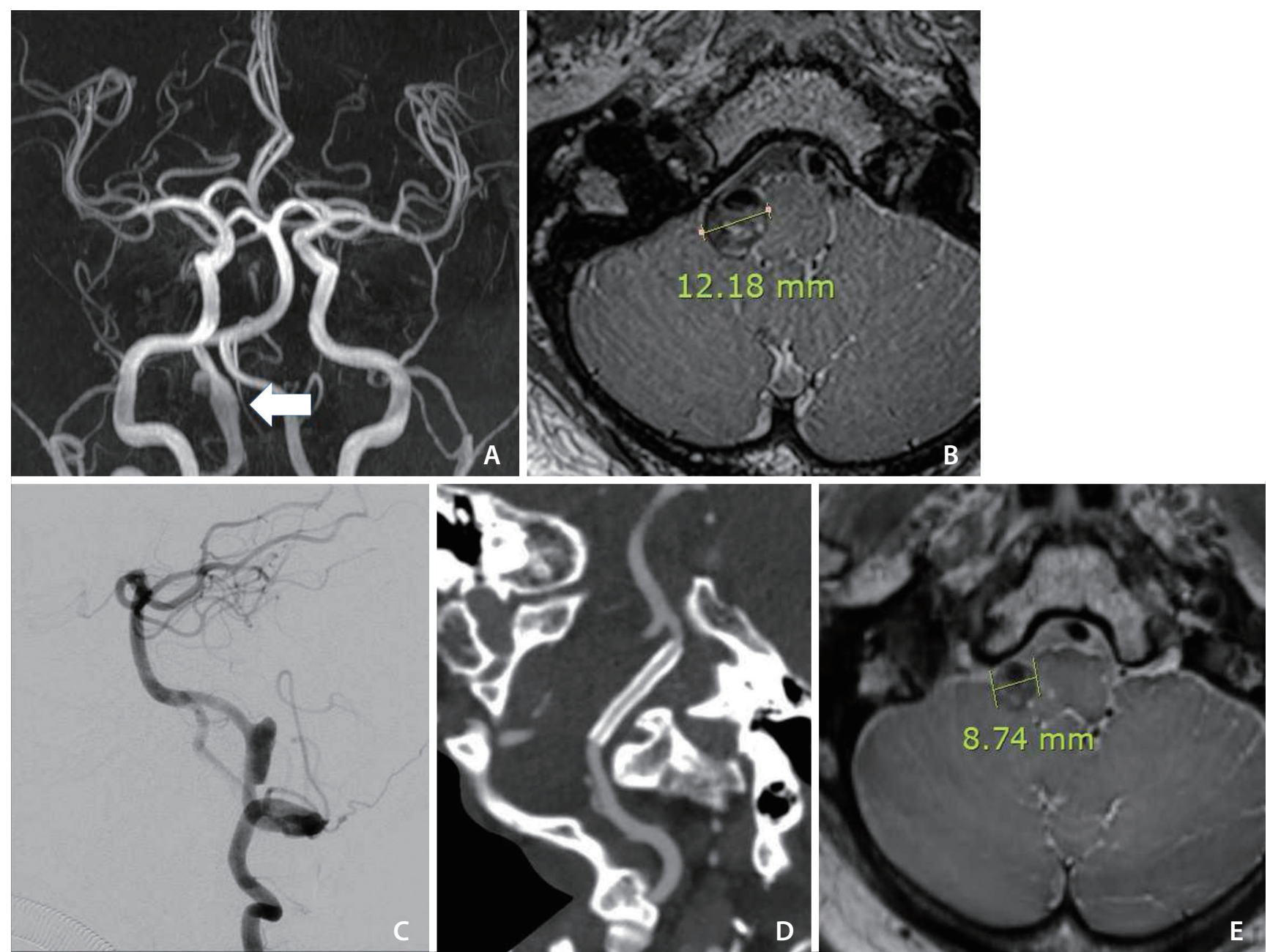

Fig. 1. A case of right vertebral artery dissecting aneurysm (VADA) with Tapia syndrome. (A) A fusiform aneurysm at the V4 segment of the right vertebral artery (white arrow) on magnetic resonance angiography. (B) High-resolution proton density weighted images show heterogeneous signal intensity surrounding the lumen of the right distal VA compressing the right side of the medulla oblongata. (C) The VADA on the lateral view of the right vertebral arteriography. (D) A Pipeline Embolization Device (PED) (Medtronic, Irvine, CA, USA) was deployed across the dissecting aneurysm, and computed tomography angiography shows the deployed PED with good wall apposition. (E) An magnetic resonance imaging performed 1 year after flow diversion shows a decrease in the VADA diameter. 
except for decreased nociception on the left side.

\section{DISCUSSION}

Most studies dealing with Tapia's syndrome focus on the peripheral variant, a multifactorial disorder characterized by unilateral paralysis of the vagus and hypoglossal nerves. ${ }^{1,3-6,8,9}$ In contrast, central Tapia's syndrome is extremely rare; it is solely caused by a lesion of the medulla oblongata and is accompanied by contralateral hemiparesis and hypesthesia?

The mechanism by which intracranial pathologic lesions cause symptoms of peripheral and central Tapia's syndromes is illustrated in Fig. 2. The hypoglossal nerve arises from the hypoglossal nucleus in the medulla and exits between the pyramid and olive. The vagus nerve exits between the olive and inferior cerebellar peduncle. The exit sites of both cranial nerves are located in the anterior medulla, while the nuclei of both nerves are located in the posterior medulla. Peripheral Tapia's syndrome may occur when the pathologic lesions are located in front of the inferior cerebellar peduncle without compression of the nuclei of lower cranial nerves, causing unilateral paralysis of the vagus and hypoglossal nerves (Fig. 2A). However, if pathologic lesions are located in the

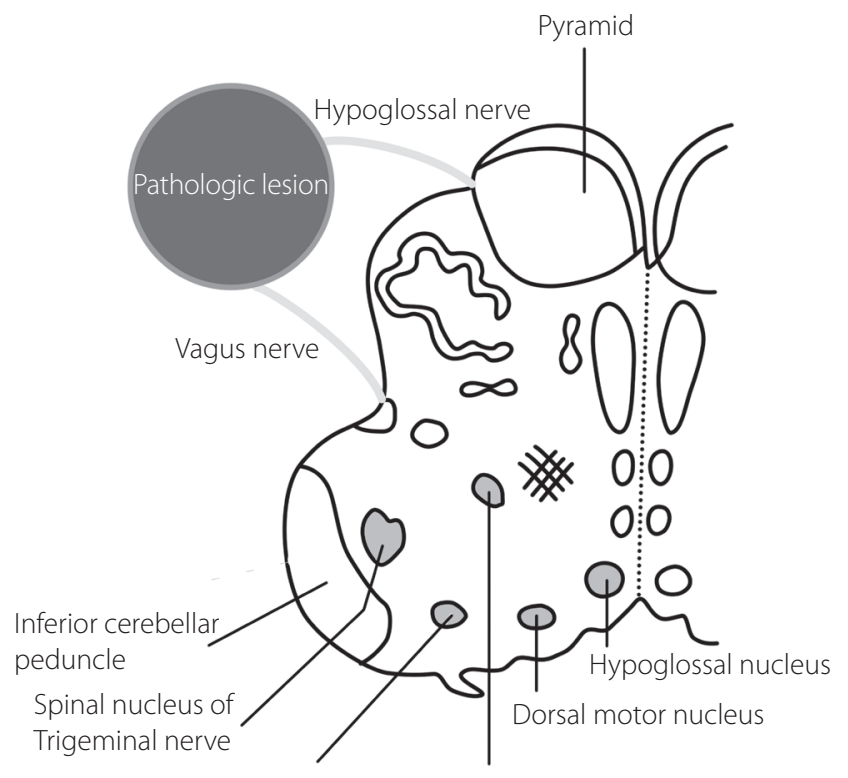

Nucleus tracts solitarius Nucleus ambiguus lateral or posterior aspects of the inferior cerebellar peduncle with compression of the nuclei of lower cranial nerves, as in our case, the vagus and hypoglossal nuclei are compressed along with the anterior and lateral spinothalamic tracts. Depending on the degree of compression, the pyramid may also be affected (Fig. 2B). Central Tapia's syndrome could occur with unilateral paralysis of the vagus and hypoglossal nerves, accompanied by contralateral hemiparesis and hypesthesia. Accordingly, our patient's symptoms could be explained by these anatomical causes and the fact that a VADA laterally compressed the inferior cerebellar peduncle.

A VADA is usually considered to be benign, and acute intervention is not always required. ${ }^{12}$ However, the nature of a VADA is still not well known, and many complications may arise depending on the degree of dissection. ${ }^{13}$ In order to treat central Tapia's syndrome caused by the VADA in this case, its mass effect on the medulla needed to be reduced.

The use of HR-MRI allows for more precise visualization of both the arterial walls and lumen in VADA cases, and thus facilitates the detection of primary and secondary features of intracranial arterial dissection. ${ }^{10}$ In our case, expansion of the dissecting aneurysm with a large mural hematoma was confirmed by HR-MRI. Symptoms were thought to be due to mechanical compression and arterial pulsation of the VADA,

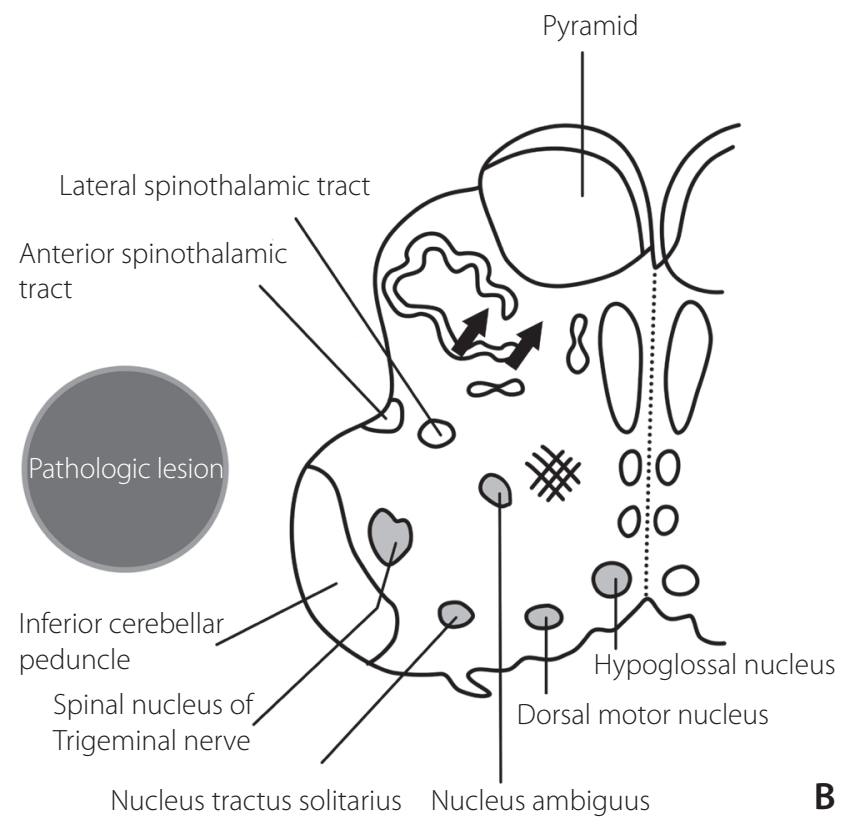

Fig. 2. Schematic drawing of a transverse section of the medulla oblongata. The exit sites of the hypoglossal and vagus nerves are located anterior to the inferior cerebellar peduncle, and the hypoglossal and vagus nuclei are located medial to the inferior cerebellar peduncle. (A) The pathologic lesion that compresses anterolateral medulla oblongata may affect the peripheral hypoglossal and vagus nerves without compressing their nuclei. (B) The pathological lesion that compresses the lateral or posterolateral side of the inferior cerebellar peduncle may affect the hypoglossal and vagus nuclei, anterior and lateral spinothalamic tracts, and pyramid (arrows) depending on the degree of compression. 
known as the water hammer effect. ${ }^{14,15}$ After treatment of the VADA with a PED, the size of the vessel wall did not change immediately. However, the symptoms improved in a short period, which could be explained by the cessation of arterial pulsation of the VADA. A follow-up HR-MRI showed a decrease in the diameter of the VADA, and clinical symptoms also improved. A VADA with brain stem compression aggravates neurologic deficits and increases in size if untreated. Treatment using a flow diverter was reported to be more effective than stent-assisted coil embolization in reducting the size of VADA and improving neurological deficits. ${ }^{16}$ We treated the patient with central Tapia's syndrome caused by a VADA with a PED in order to reduce compression on the medulla. Symptoms improved by reducing arterial pulsation and decreasing mechanical compression of the VADA. In summary, we consider an endovascular PED to be a valuable treatment option for a VADA underlying central Tapia's syndrome. Further research is needed about its applicability under other circumstances.

\section{Fund}

None.

\section{Ethics Statement}

This case report was approved by the Institutional Review Board (Inje Universty Busan Paik Hospital Institutional Bioethics (ommittee) and conducted according to the criteria set by the declaration of Helsinki. Since the consent for publication was not available for the patient in this case report, the patient's information was anonymized by removing the sex and specific age.

\section{Conflicts of Interest}

The authors have no conflicts to disclose.

\section{Author Contribution}

Concept and design: SK and JHP. Analysis and interpretation: YWS, SK, and JHP. Data collection: YWS and SK. Writing the article: YWS and JHP. Critical revision of the article: SK, JWB, HGL, JHK, SHP, SYP, SJ, HWJ, and YGJ. Final approval of the article: JHP, JWB, HGL, JHK, SHP, SYP, SJ, HWJ, and YGJ. Statistical analysis: SK.

\section{ORCID}

Yong Woo Shim: https://orcid.org/0000-0002-9364-0976

Jung Hyun Park: https://orcid.org/0000-0001-7512-0400
Sung-Tae Kim: https://orcid.org/0000-0002-3737-3850

Jin Wook Baek: https://orcid.org/0000-0003-4632-4951

Hyun Gon Lee: https://orcid.org/0000-0002-0980-3710

Jung Hae Ko: https://orcid.org/0000-0002-0029-6847

Sung Hwa Paeng: https://orcid.org/0000-0002-8903-9117

Se Young Pyo: https://orcid.org/0000-0002-6578-6361

Sung-Chul Jin: https://orcid.org/0000-0001-5282-9329

Hae Woong Jeong: https://orcid.org/0000-0002-4912-9302

Young Gyun Jeong: https://orcid.org/0000-0002-8068-2878

\section{REFERENCES}

1. Tapia AG. [A new syndrome; few cases of hemiplegia larynx and language with or without sterone-crypto-palsy. Mastoid and trapeze]. Arch Int Laryngol Otol Rhinol 1906;22:780-785 French

2. Al-Sihan M Jr, Schumacher M, Löhle E. Tapia syndrome caused by a vertebral artery dissection. Ear Nose Throat J 2011;90:313314

3. Andrioli G, Rigobello L, Mingrino S, Toso V. Tapia's syndrome caused by a neurofibroma of the hypoglossal and vagus nerves: case report. J Neurosurg 1980;52:730-732

4. de Freitas MR, Nascimento OJ, Chimelli L. Tapia's syndrome caused by Paracoccidioidis brasiliensis. J Neurol Sci 1991;103:179181

5. Shimohata T, Nakano R, Sato S, Tsuji S. [A patient with aneurysm of extracranial internal carotid artery presenting lower cranial polyneuropathy similar to Tapia's syndrome]. Rinsho Shinkeigaku 1994;34:707-711 Japanese

6. Boisseau N, Rabarijaona H, Grimaud D, Raucoules-Aimé M. Tapia's syndrome following shoulder surgery. Br J Anaesth 2002;88:869-870

7. Krasnianski M, Neudecker S, Schlüter A, Krause U, Winterholler M. Central Tapia's syndrome ("matador's disease") caused by metastatic hemangiosarcoma. Neurology 2003;61:868-869

8. Sotiriou K, Balanika M, Anagnostopoulou S, Gomatos C, Karakitsos D, Saranteas T. Postoperative airway obstruction due to Tapia's syndrome after coronary bypass grafting surgery. Eur $J$ Anaesthesiol 2007;24:378-379

9. Tesei F, Poveda LM, Strali W, Tosi L, Magnani G, Farneti G. Unilateral laryngeal and hypoglossal paralysis (Tapia's syndrome) following rhinoplasty in general anaesthesia: case report and review of the literature. Acta Otorhinolaryngol Ital 2006;26:219221

10. Chun DH, Kim ST, Jeong YG, Jeong HW. High-resolution magnetic resonance imaging of intracranial vertebral artery dissect- 
ing aneurysm for planning of endovascular treatment. J Korean Neurosurg Soc 2015;58:155-158

11. O'kelly CJ, Krings T, Fiorella D, Marotta TR. A novel grading scale for the angiographic assessment of intracranial aneurysms treated using flow diverting stents. Interv Neuroradiol 2010;16:133-137

12. Kai Y, Nishi T, Watanabe M, Morioka M, Hirano T, Yano S, et al. Strategy for treating unruptured vertebral artery dissecting aneurysms. Neurosurgery 2011;69:1085-1091; discussion 10911092

13. Kobayashi N, Murayama Y, Yuki I, Ishibashi T, Ebara M, Arakawa H, et al. Natural course of dissecting vertebrobasilar artery aneu- rysms without stroke. AJNR Am J Neuroradio/ 2014;35:1371-1375

14. Kassis SZ, Jouanneau E, Tahon FB, Salkine F, Perrin G, Turjman F. Recovery of third nerve palsy after endovascular treatment of posterior communicating artery aneurysms. World Neurosurg 2010;73:11-16; discussion e2

15. Ko JH, Kim YJ. Oculomotor nerve palsy caused by posterior communicating artery aneurysm: evaluation of symptoms after endovascular treatment. Interv Neuroradiol 2011;17:415-419

16. Cho DY, Kim BS, Choi JH, Park YK, Shin YS. The fate of unruptured intracranial vertebrobasilar dissecting aneurysm with brain stem compression according to different treatment modalities. AJNR Am J Neuroradiol 2019;40:1924-1931 